\title{
Framework for the environmental impact assessment of operational shipping
}

\author{
Jana Moldanová (D), Ida-Maja Hassellöv, Volker Matthias, \\ Erik Fridell, Jukka-Pekka Jalkanen, Erik Ytreberg, \\ Markus Quante, Jenny Tröltzsch, Ilja Maljutenko, Urmas Raudsepp, \\ K. Martin Eriksson
}

Received: 25 February 2021/Revised: 28 May 2021/Accepted: 28 June 2021/Published online: 22 July 2021

\begin{abstract}
Shipping is an important source of pollution affecting both atmospheric and aquatic environments. To allow for efficient mitigation of environmental degradation, it is essential to know the extent of the impacts of shipping in relation to other sources of pollution. Here, we give a perspective on a holistic approach to studies of the environmental impacts of operational shipping through presentation of an assessment framework developed and applied on a case of shipping in the Baltic Sea. Through transfer of knowledge and concepts, previously used in assessments of air pollution, now applied to assessments of marine pollution and underwater noise, the horizon of understanding of shipping-related impacts is significantly improved. It identifies the main areas of environmental degradation caused by shipping and potential improvements through legislation and technological development. However, as the vast majority of contaminants discharged into the sea are not routinely monitored and assessed, the links between pressure of contaminants from shipping and environmental state and impacts will not be caught in the current environmental regulatory frameworks.
\end{abstract}

Keywords Air pollution - DPSIR assessment framework . Marine pollution - Shipping - Underwater noise

\section{INTRODUCTION}

Shipping is an important economic sector, responsible for transporting the majority of goods around the globe. Even though shipping freight is energy efficient in comparison with other transport sectors, there is an increasing awareness that impacts of shipping on the environment can be considerable. Some aspects of its impact on the marine environment, air quality and coastal land ecosystems, resulting from, e.g. oil spill, emissions of air pollutants and release of hazardous substances to the sea, have been recognised for several decades. Impacts of various operations on board of vessels on the environment have to some extent been regulated, mainly through conventions of the International Maritime Organization (IMO). However, the work within IMO is known to be protracted and, compared to pollution from land-based sources, the regulation of pollution from ships has in many areas been weak. It is recognised that this, in combination with a steady growth of the sector, has led to a high relative contribution of shipping to the anthropogenic burden of many pollutants, both at sea and on land. A more systematic knowledge of the numerous harmful substances emitted by shipping and their impacts on all parts of the environment is, however, largely missing. Here, we build a framework for systematising available and future knowledge in a holistic manner to support prospective decision making.

Historically, the environmental regulation of shipping has mainly been reactive, driven by events where the environmental damage caused by shipping was catastrophic. Examples include several tanker accidents with major oil spills in 1976-1977, which led to the adoption of the International Convention for the Prevention of Pollution from ships (MARPOL) protocol in 1978. Another example is damages to oyster farming in France observed in the late 1970s, soon after introduction of organotins (TBT) in antifouling paints, and eventually the adoption (in 2001) of the International Convention on the Control of Harmful Antifouling Systems on Ships (AFS convention), prohibiting the use of harmful organotins in antifouling paints on ships. In the recent decade, there has been an increasing pressure on more stringent regulation of international shipping with respect to the release of pollutants to 
water and air, where shipping is one of many anthropogenic contributors leading to a violation of environmental quality standards (HELCOM Baltic Sea Action Plan, BSAP, https://helcom.fi/media/documents/BSAP_ Final.pdf; European Sustainable Shipping Forum, ESSF, https://ec.europa.eu/transport/themes/sustainable/essf_en). New regulations have entered into force or have been decided upon, either globally or in specific regions. Examples are the global limit on fuel sulphur content to limit emissions of sulphur oxides that entered into force in January 2020 (IMO Resolution MEPC.305(73)), or the regional limit on emissions of oxides of nitrogen to the air from newly built ships in the Baltic Sea, North Sea and the English Channel, adopted by the IMO in 2017, which entered into force in January 2021, as well as regulations of ballast water that entered into force in 2017 (IMO Resolution BWM/CONF/36) and stepwise limits for sewage release (IMO resolution MEPC.284.(70)). Recently, the IMO has agreed on a roadmap for substantial reduction of greenhouse gas emissions from shipping (50\% by 2050; IMO Resolution MEPC 304(72)) which requires, along with maximum technically feasible energy effectivisation, a shift from the use of fossil fuels to fossil-carbon-free alternatives such as biofuels, hydrogen, electric propulsion or ammonia. This will also have a large impact on emissions and discharges of other pollutants, especially of those associated with combustion and handling of the fuels. Decarbonisation is expected to bring decreasing emission trends in general; however, some of the new emerging fuels and technologies could also constitute new threats to different parts of the environment. To develop efficient mitigation strategies for pollution from shipping, a holistic assessment of all emissions from shipping to all compartments of the environment is urgently needed.

Previous efforts to include an assessment of shipping as one out of many sectors impacting the marine environment do not enable decision support on plausible mitigation strategies for pollution from shipping as they are aggregated at too high levels (e.g. Robinson et al. 2014). As society requires motivation of investments into environmental measures, such as abatement technologies and cleaner fuels, with avoided damage costs, the assessment of the impacts and their economic valuation needs to be as complete and as quantitative as possible. A complete assessment is also needed to avoid abatement measures that transfer problems from one compartment of the environment to another (Endres et al. 2018). In this paper, we give a perspective on development of a quantitative holistic assessment framework for shipping through description of the framework that has been developed within the BONUS SHEBA project (Shipping and the Environment of the Baltic Sea Region, www.sheba-project.eu). The framework has been developed and prepared for full implementation, as far as the current state of knowledge allows, and maps the path towards a complete quantitative assessment. The framework presents, for the first time, a structure allowing for holistic assessment of how shipping impacts both the environmental indicators and descriptors of relevant EU directives and human wellbeing. Compared to other general frameworks that include shipping, this approach is unique as it assesses the different ship-based subsystems (e.g. emissions to air, discharges of sewage or bilge water, leakage of antifouling paints) separately, enabling analysis of both the total impact of shipping as well as the contributions from the respective subsystems. Both can then be used to evaluate different policy options. While the detailed methodology and results are described elsewhere (Jalkanen et al. 2018, 2021a; Karl et al. 2019a, c; Maljutenko et al. 2021; Ramacher et al. 2020a, b; Raudsepp et al. 2019a; Tang et al. 2020; Ytreberg et al. 2020), the framework concept is presented here together with the main knowledge gaps and an outline of a possible further development of the framework. The framework was elaborated for the case of the Baltic Sea region, but it is generic and can be applied to other geographic regions and/or for global assessments. The Baltic Sea region, one of the areas most heavily impacted by anthropogenic activities in general and at the same time one of the world's regions with the most intense shipping and also advanced legislation targeting its environmental impacts, is a good model area to study the mitigation strategies for pollution from shipping (HELCOM 2018a).

\section{ASSESSMENT FRAMEWORK}

In order to investigate the effects of shipping on the environment in the Baltic Sea area, a classical DPSIR framework, Driver-Pressure-State-Impact-Response (Fig. 1), is used. Applied to different future scenarios, it enables analysis of options for regulations and other policy measures that aim at reduced pressures, improved state and minimised impacts on human health and ecosystem services.

Drivers in this DPSIR framework are the shipping activities governed by socio-economic drivers and policies, the latter are recognised as indirect drivers. Ship traffic causes pressures on the environment, the atmosphere, the water body, and the entire ecosystem. These pressures consist of, e.g. not only emissions and discharges of pollutants to air and water but also spreading of non-indigenous species (NIS) and underwater noise. The emissions lead to elevated pollutant concentrations in air and water and to noise levels under water, which in turn can lead to ecosystem changes, such as, e.g. loss of marine species. These effects are described as state, i.e. pressure-induced 


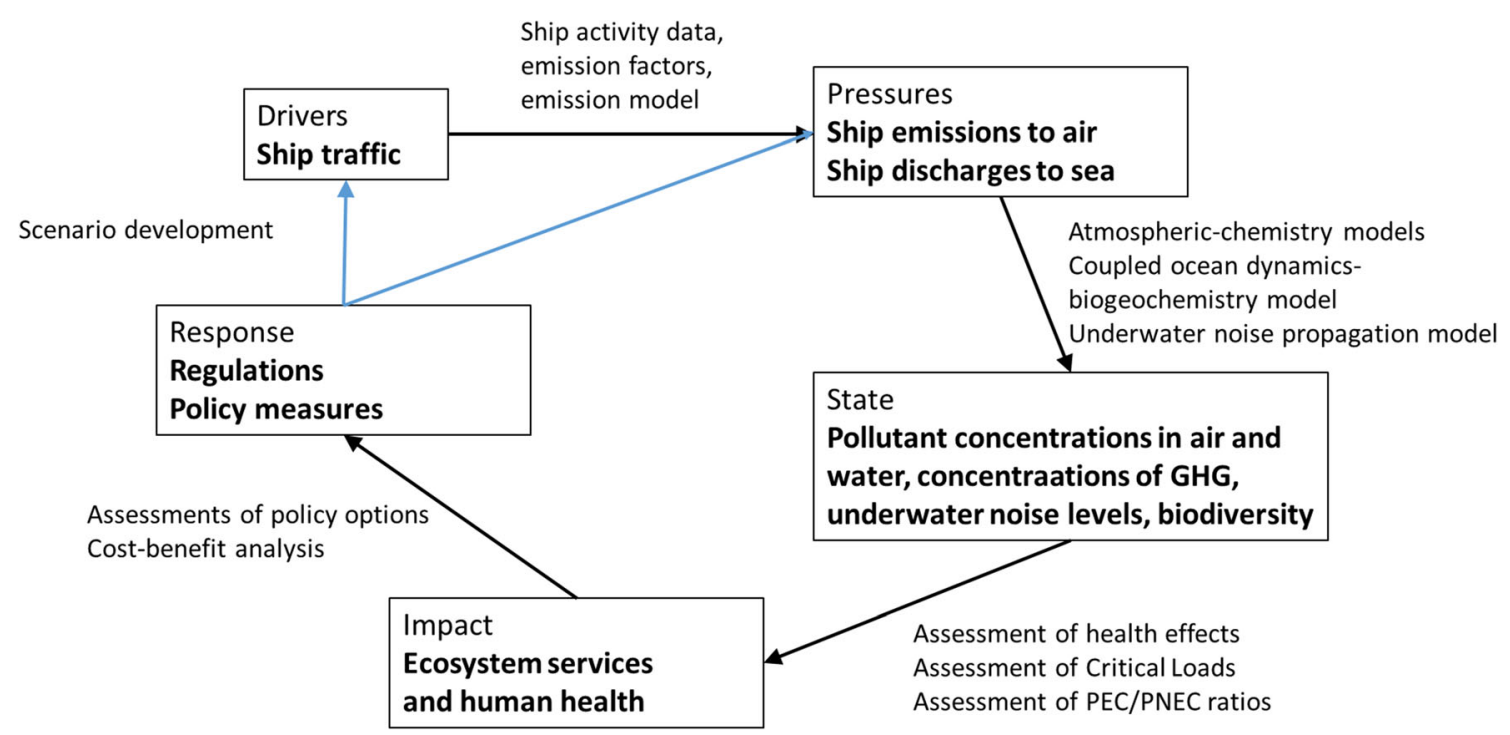

Fig. 1 The DPSIR framework for assessment of operational shipping. The information provided beside the arrows indicates tools and activities which are in use to step from one DPSIR element to the next. The blue arrows indicate the step from one assessment loop to the next one evaluating the responses found in the first loop

changes leading to a modified state of the environment. The changed state, in turn, causes changes in intermediate and final ecosystem services and in effects on human health, described as impacts on human wellbeing. Reductions of these impacts are achieved through regulations or other policy measures, technical measures as well as societal or economic adaptation, described as response, which may influence the drivers as well as the pressures (from shipping).

The aim of the framework (Fig. 1) is to assess the impacts of numerous pressures from shipping, generated often from several on-board operations in different subsystems of the ship (Fig. 2), and already adopted or potential responses to these impacts. To derive direct links to shipping pressures, the detailed subsystems which directly cause the effects on the environment must be identified. Emissions to air are mostly caused by main and auxiliary engine and boiler operations. The main subsystem regarding the underwater noise are the ship hull, engines and propellers. For discharges to sea, the subsystems comprise antifouling paint on the hulls, ballast water release, biofouling on ship hull, release of bilge water (contaminated water collected at the bottom of the hull), black water (wastewater from toilets), grey water (wastewater from sinks, baths, washing machines and other kitchen appliances), scrubber wash water (wastewater from exhaust after treatment), stern tube oil (mineral oil in the stern tube lubricating bearings supporting the propeller shaft, contained by shaft seals with certain operational leakage) and solid waste (Fig. 2). The large number of different pollutants demands development of a model system that can calculate all these pressures and their consequences in a consistent manner.
In the BONUS SHEBA framework, the Drivers, Pressures, State, Impacts and Responses are linked through numerical or conceptual models. Feeding the results from one to another subsequent model allows for a quantitative analysis of the environmental impact caused by ships' operations.

\section{FRAMEWORK APPLIED TO THE BALTIC SEA REGION}

\section{Drivers}

The ship types considered in the BONUS SHEBA framework are those most relevant for the Baltic Sea, i.e. container/cargo ships including ro-ro (roll-on-roll-off) ships, tankers, ferries including ro-pax (combined passenger-roro) ships, cruise ships and fishing vessels. Global drivers such as the world economy, societal changes and resource use will continue to have a great impact over future decades on demand for commercial shipping and fishing vessels. Nevertheless, the market dynamics (e.g. supply and demand) of the specific sectors, including regional variances, will lead to short- and mid-term shifts in growth patterns which will in turn affect trends in commercial shipping related to the commodities traded. For example, high growth economies will create demand for bulk and tank shipping and containerised goods (DNV 2012). Shipping activity is expected to continue to grow as the world economy develops and the trend with larger ships is expected to continue since this gives economic advantages and more fuel-efficient transport systems. While sectors 


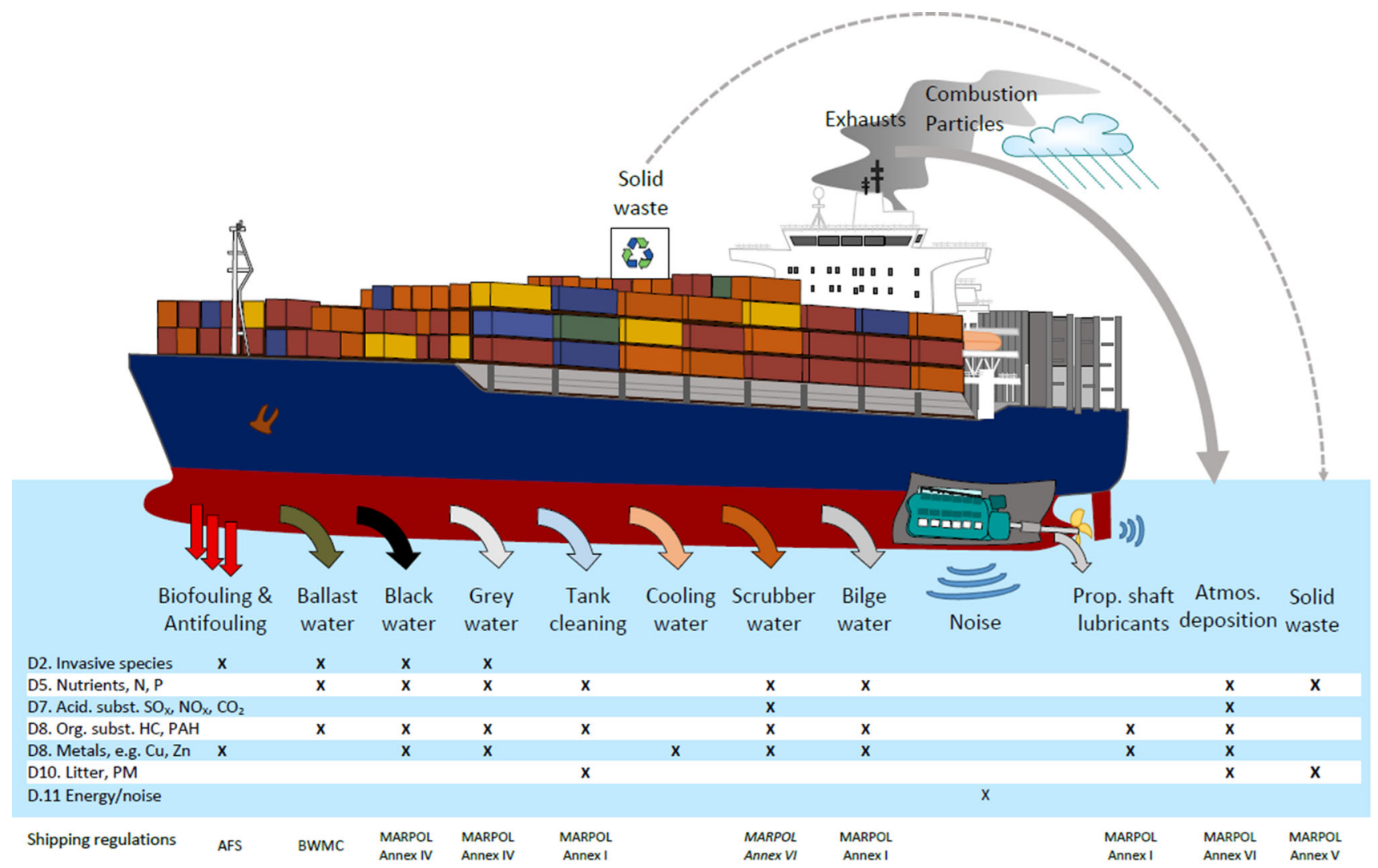

Fig. 2 Shipping-related subsystems used to calculate emission factors of nutrients, acidifying substances, contaminants, NIS and underwater noise. The labelling D2-D11 refers to the descriptors in the Marine Framework Strategy Directive (2008/56/EC) related to these pressures: D2non-indigenous species do not adversely alter the ecosystem, D5-human-induced eutrophication is minimised, D7-permanent alteration of hydrographical conditions does not adversely affect marine ecosystems, D8 - concentrations of contaminants are at levels not giving rise to pollution effects, D10 - marine litter do not cause harm to the coastal and marine environment, and D11—introduction of energy, including underwater noise, is at levels that do not adversely affect the marine environment. The bottom row shows the responses (legislation) already adopted by IMO (AFS - International Convention on the Control of Harmful Antifouling Systems on Ships; BWMC-Ballast water management convention) (from Jalkanen et al. 2021a, their Fig. 1)

like container shipping are expected to grow, the development of tankers and dry bulk, much associated with transportation of fossil fuel, will depend on the degree of decarbonisation. Problems with congestion on land could also give an increase in short sea and inland shipping.

The Baltic Sea is a major trade route for the export of Russian petroleum products, and it is estimated that about 2,000 ships are at sea at any time, while 150-200 large oil tankers are harboured in twenty ports around the sea each day (HELCOM 2018a). In addition to transporting goods, the Baltic Sea also has some of the highest passenger rates in Europe, with eight of the top twenty ports for passengers embarking and disembarking.

\section{From drivers to pressures}

Historically, different methods for the construction of emission inventories of the different pressures have been used, utilising numerous top-down (based on total bunker sales, cargo volume or similar), bottom-up (based on shipping activities) or combined methodologies. In this framework, we apply the state-of-the-art methodology based on ship traffic activities, derived from ship position data transmitted in high temporal resolution via AIS (Automatic Identification System) signals. The total amount of air pollutant emissions and discharges to sea as well as of underwater noise emitted from ships sailing in the Baltic Sea region are calculated in a consistent manner with the STEAM model (Jalkanen et al. 2009, 2012, 2018, 2021a). The model combines shipping activities with emission factors for air pollutants sulphur and nitrogen oxides, particulate matter, carbon monoxide $\left(\mathrm{SO}_{X}, \mathrm{NO}_{X}, \mathrm{PM}, \mathrm{CO}\right)$ and $\mathrm{CO}_{2}$. In the recent new development, also water pollutants (nutrients, i.e. $\mathrm{P}$ and $\mathrm{N}$; contaminants, i.e. metals and volumes of various waste streams) and underwater noise were calculated. Consequently, maps of emission to air and discharges to the sea are generated in high spatial and temporal resolution. 


\section{Pressures}

\section{Emissions to air}

The main air pollutants emitted by shipping are $\mathrm{SO}_{X}$ and $\mathrm{NO}_{X}$ as well as particulate matter. Particles directly emitted in the exhaust typically contain mineral ash, metals, black carbon (soot), condensable organics and sulphate. These particles, when leaving the ship stack, are very small (diameter below $0.1 \mu \mathrm{m}$ ). During ageing of the emissions in the atmosphere, secondary particulate matter is formed when the ship exhaust gases are oxidised and react with other pollutants like ammonia and volatile organics. In aged air masses, this secondary PM largely exceeds the primary PM. Shipping also contributes to air pollution with emissions of carbon monoxide, volatile organic compounds (VOC) and polyaromatic hydrocarbons (PAH). Besides influencing particle formation, nitrogen oxides and VOC emitted by shipping affect tropospheric ozone formation.

Regarding the effect of shipping on climate, the sector is responsible for about $3 \%$ of the total anthropogenic $\mathrm{CO}_{2}$ emissions (Faber et al. 2020). Use of halogenated hydrocarbons and ozone depleting substances, applied for cargo space cooling and in air conditioning systems, most notably aboard refrigerated cargo, fishing and passenger vessels, should be gradually phased out. However, their replacements, hydrofluorocarbon (HFC) coolants, have significant global warming potential. Emissions of these substances constitute about two percent of the total $\mathrm{CO}_{2}$ equivalent emissions from ships (Faber et al. 2020). Use of Liquified Natural Gas (LNG) as marine fuel mitigates emissions of traditional air pollutants, like $\mathrm{NO}_{X}, \mathrm{SO}_{X}$ and PM. Careful attention to technical features preventing the loss of methane during ship operation is, however, needed. If unburned methane escapes from ships, use of LNG may lead to larger climate impact than use of diesel fuels.

\section{Discharges to sea}

Direct pressures from shipping on the marine environment arise from different types of waste waters containing contaminants, acidifying substances and nutrients, as well as NIS from ballast water and ship hulls (Fig. 2). Contaminants are present in different ship-based subsystems ranging from metals and organic biocides in antifouling paints and scrubber water, to oily residues and PAHs from rests of fuels and lubricants, together with ten sides in bilge water. Nutrients are mainly present in grey and black water and food waste but may also come from bilge and scrubber water and treated ballast water. Invasive species can be spread from shipping to the Baltic Sea primarily via the subsystems ballast water and biofouling on hulls. Acidifying substances are primarily entering the marine environment through atmospheric deposition of sulphur and nitrogen oxides from ships exhaust on the sea surface, considered an indirect pressure. Following the stricter global sulphur legislation from Jan 2015 in SECAs, respectively from Jan 2020 globally, there is also an increasing number of ships operating in the Baltic Sea equipped with scrubbers. Scrubbers imply direct pressure through transfer of sulphuric and nitric acid from the exhaust directly to the marine environment, an individual ship may produce hundreds of tonnes of acidified water of pH $\sim 3$ per hour (Hassellöv et al. 2013). An additional indirect pressure is deposition of particulate matter related to ships exhaust containing i.e. soot, PAHs and metals. The total amount of one specific contaminant from a single ship may originate from several subsystems. For example, copper emitted from a ship may originate from antifouling paints, cooling-, bilge- and scrubber water.

\section{Emissions of underwater noise}

Natural and anthropogenic activities can generate loud underwater noise, which can disturb marine life (Durate et al. 2021). Compared to emission inventories of air pollutants and discharges to the sea, systematic inventories of underwater noise have been until recently largely missing. Within the BONUS SHEBA framework, a novel modelling tool to indicate the levels of noise emitted by ships was developed combining a ship noise source model with ship traffic activity data (Jalkanen et al. 2018). This model development advances our knowledge of spatio-temporal variation of shipping noise and increases general knowledge of ships as a source of noise pollution.

\section{From pressure to state}

To understand how the pressures affect the state of the environment and the different indicators set by environmental legislation, the cumulative knowledge on dispersion, transport, chemical, physical and biological transformation and mutual interactions of these pressures is typically collected in atmospheric, oceanic, soil and other models of various degrees of complexity. For a complex assessment covering different compartments of the environment, as in this case, some of these models need to be coupled, either off-line through output-input data, or online, if two-way interaction is needed. In BONUS SHEBA, the assessment was taken further by including three regional Eulerian atmospheric chemistry transport models (CTMs) (Karl et al. 2019a), a coupled ocean hydrodynamic_-biogeochemical model as well as an underwater noise propagation model, which all were fed with emissions of the shipping-related pollutants calculated by the STEAM model described earlier. 
Air pollution and climate

A number of CTMs have been applied in assessment of shipping emissions on different geographic scales from global to local, e.g. Karl et al. (2019a) present three different CTMs and show their intercomparison for the Baltic Sea region. In the BONUS SHEBA framework, the contribution of shipping emissions to the concentrations of different air pollutants is modelled on multiple geographic scales and includes dispersion of pollutants as well as formation of secondary pollutants such as particles and ozone. The modelled area starts at the European level, resulting in air pollutant contribution on relatively coarse resolution, is more detailed for the Baltic and North Seas (4 x $4 \mathrm{~km})$ and, finally, with high resolution $(1 \times 1 \mathrm{~km}$ and finer) for selected port cities. For the regional modelling, a state-of-the-art atmospheric chemistry transport model (CTM) CMAQ (Byun and Schere 2006) is used to calculate concentrations of air pollutants (among others $\mathrm{NO}_{2}, \mathrm{O}_{3}$, as well as $\mathrm{NO}_{3}{ }^{-}$and $\mathrm{SO}_{4}{ }^{2-}$ in aerosol particles) for the entire Europe and for the Baltic Sea. To assess in more detail the impact from ship emissions on air pollution in selected port cities, two city-scale models TAPM (Hurley et al. 2005) and Episode CityChem (Karl et al. 2019b) are applied, using concentration fields of the regional CTMs for boundary conditions (Ramacher et al. 2020a, b; Tang et al. 2020).

Effects of shipping on climate include primary impacts of long-lived greenhouse gases, complex primary and secondary impacts from short-lived climate-forcing pollutants (SLCPs) including $\mathrm{NO}_{X}$ and particulate matter (Eyring et al. 2010), as well as a number of feedbacks including release of $\mathrm{CO}_{2}$ from loss of alkalinity due to direct release or deposition of acids to seawater, change of albedo due to soot deposition on snow and ice surfaces or changes in primary production due to changes in marine ecosystems. The impacts of SLCPs include positive forcing from ozone and negative forcing from methane, both related to emissions of NOx, as well as direct forcing of emitted particles (positive for soot, negative for sulphate and organic matter) and their indirect effect through changes in cloud microphysics (negative forcing) and decrease of surface albedo in polar region due to deposition of soot particles on snow (positive forcing) (Sofiev et al. 2018). The complex connection between emissions, global climate change and regional climate change is not addressed by the atmospheric modelling, however, global climate impact of long-lived climate gases emitted by shipping is treated in terms of $\mathrm{CO}_{2}$ eq emissions (on a 100-y horizon) to consider the climate change issue in the assessment.

\section{Marine pollution}

To model how the pressure from shipping results in a changed state of the marine environment, modelling of both direct discharges and indirect sea-surface deposition of pollutants stemming from ship's exhaust need to be considered, typically in oceanic models of different geographic scales and complexity regarding description of the transport, mixing and chemical and biological processes. In the BONUS SHEBA framework, an ocean circulation model coupled to a biogeochemical model is applied (Raudsepp et al. 2019a). The full 3-dimensional oceandynamic modelling is completed with a set of more detailed case studies made for a set of ports and ship lanes with a separate model with simplified transport, developed for the assessment of impacts of antifouling paints.

The shipping-related pollutants discharged directly to the water column are calculated with STEAM and air pollutants are introduced to the oceanic models through the model deposition fields from regional-scale simulations of the CTM CMAQ. Distribution and transport of marine pollution from shipping are modelled with a three-dimensional simulation setup of hydrodynamic model GETM (Burchard and Bolding 2002) covering the Baltic Sea domain with 1 nautical mile resolution $(1.852 \mathrm{~km})$. For modelling of nutrient cycling, GETM is coupled with the biogeochemical model ERGOM (Neumann 2000). For modelling of contaminants, GETM is coupled with a tracer-transport model without any chemical processes included. Outputs of shipping emissions and atmospheric deposition have hourly resolution and result in hourly inputs of nutrients/contaminants on horizontal resolution similar to that of GETM which are assumed to be instantly dispersed over the uppermost gridcells of GETM (vertically corresponding to the mixed layer depth).

For modelling of contaminants in a set of ports and shipping lanes, the MAMPEC 3.1 model is used to calculate site specific Predicted Environmental Concentrations (PEC) (van Hattum et al. 2002; Ytreberg et al. 2020). The emitted amounts of contaminants are calculated from the volumes of ballast water, bilge water, scrubber water, grey water and black water calculated by the STEAM model and the concentrations of contaminants in these discharges, while the amounts of antifouling compounds were retrieved directly from the STEAM model output.

\section{Noise propagation}

Analogous to atmospheric or oceanic emission modelling, emissions of underwater noise only describe the source of pollution, whereas to describe the noise experienced by 
marine fauna, noise propagation modelling comprehending 3D seafloor map including its composition as well as salinity/temperature vertical profiles needs to be employed. Modelling the whole of the Baltic Sea could not be employed in the framework because of limitations in computational resources, the noise propagation model is, therefore, employed in pilot site locations to produce noise "concentrations" as a first step to better understand the propagation of noise from shipping.

\section{State}

\section{Air pollution}

The main air pollution parameters which are relevant for further assessment of shipping-related impacts are ambient concentrations of particulate matter, ozone and $\mathrm{NO}_{2}$, having negative health impacts, and deposition of nitrate and sulphate, causing acidification and eutrophication of both marine and coastal ecosystems. In addition, emissions of toxic species, such as polyaromatic hydrocarbons (PAHs) or metals may be of interest, especially when discussing effects of certain abatement measures. The state indicators addressing the health impacts are the air quality objectives and limit values for the air pollutants in question, and the impacts on land ecosystems are in the form of critical loads and levels of atmospheric deposition of eutrophying and acidifying substances and ozone. Model studies of global and regional effects of shipping on air pollution show that the largest contributions of shipping to air pollution are in coastal regions and along the major shipping routes. Globally, the calculated contribution of shipping to $\mathrm{PM}_{2.5}$ concentrations is up to $2 \mu \mathrm{g} / \mathrm{m}^{3}$ (ambient background $\mathrm{PM}_{2.5}$ concentrations are few to few tenths $\mu \mathrm{g} / \mathrm{m}^{3}$ ) (Sofiev et al. 2018). Contribution to ozone concentrations in Europe was calculated to 2-4 ppb (5-15\%) (Eyring et al. 2010 and references therein). For the Baltic Sea area, effects of shipping emissions on concentrations of air pollutants and deposition of sulphate and nitrate have been calculated for before and after the implementation of the strengthened SECA regulation in 2015 as well as for several future scenarios by Jonson et al. (2019) and within this framework by Karl et al. (2019a, b) showing that shipping contributes under year 2012 conditions by about $20-30 \%$ to the modelled concentrations of $\mathrm{NO}_{2}$ and 5-20\% to secondary PM species in coastal areas. Along the shipping lines, the annual mean $\mathrm{NO}_{2}$ concentrations modelled in Karl et al. (2019a) are reaching up to $>8 \mu \mathrm{g} / \mathrm{m}^{3}$ which are concentrations corresponding to those typically observed in smaller cities.

Additional hot spots of shipping-related air pollution are port cities where emissions from harbour operations may add to those from operational shipping to further deteriorate the local air quality. For Hamburg, for example, it has been estimated that about $60 \%$ of the $\mathrm{NO}_{2}$ and $40 \%$ of the $\mathrm{PM}_{2.5}$ annual mean concentrations in the greater harbour area (for the year 2012) are due to shipping emissions (Ramacher et al. 2020b). European cities often exceed EU limit values for annual average $\mathrm{NO}_{2}$ concentrations and ship emissions contribute a non-negligible fraction to this.

\section{Marine pollution}

The pressure of different pollution from shipping (NIS, nutrients, acidifying substances, contaminants, solid waste) may affect the marine environmental state characterised by descriptors D2, D5, D7, D8 and D10 of the Marine Strategy Framework Directive (MSFD, 2008/56/EC) (Fig. 2). The state of the Baltic Sea as assessed by HELCOM (2018a) shows that good environmental status is not reached with respect to nutrients and hazardous substances. Large-scale effects of pollution by shipping have previously been shown for TBT from antifouling paints along shipping routes (Ten Hallers-Tjabbes et al. 1994). More recent studies have pointed out that shipping significantly contributes to ocean acidification in intensively trafficked areas with modelled seasonal acidification of $0.0015-0.002 \mathrm{pH}$ (Hassellöv et al. 2013). Atmospheric deposition and direct discharge of nutrients from different waste streams contribute to the increase of spring phytoplankton biomass and decrease of oxygen content in the Baltic Sea (Raudsepp et al. 2019a). Spreading of invasive NIS, both from ballast water handling and biofouling on ship hulls, is estimated to account for close to $50 \%$ of the newly introduced NIS in the Baltic Sea. In the period 2011-2016, 12 new NIS were observed, implying that the HELCOM core indicator for good status is not reached (HELCOM 2018a).

\section{Underwater noise}

All sound present in a particular location and time, including natural and anthropogenic sounds, comprises a soundscape (Durate et al. 2021). Research has shown that over the last 50 years, there have been increases in ambient noise, mostly due to the shipping activity (Van der Graaf et al. 2012 and references therein). Underwater noise from marine traffic is currently recognised as a threat to the health of the marine species and MSFD descriptor D11 (Fig. 2) specifies indicators to assess the environmental status of marine habitats with respect to low-frequency continuous sound. Low-frequency noise, relevant for fish hearing, can be heard from hundreds of $\mathrm{km}$ away from the noise source, whereas high-frequency noise attenuates faster. The member states are required to monitor and/or model underwater sound, and to consider the trends in the ambient noise level in certain frequency bands. Shipping also greatly contributes to the soundscape of the Baltic Sea 
(project BIAS-Baltic Sea Information of the Acoustic Soundscape). Here, the sound level in the $63 \mathrm{~Hz}$ and 125 $\mathrm{Hz}$ bands correlated with the distance to the closest ship even up to the distance of $15 \mathrm{~km}$ (Sairanen 2014).

\section{From state to impacts}

Assessment of impacts of shipping in BONUS SHEBA builds upon assessment frameworks that were developed for protection of human health and of land, freshwater, coastal and marine ecosystems from anthropogenic pollution in and around Europe and which have been used to design and update the appropriate EU directives. The Air Quality Directive 2008/50/EC (AQD) covers air quality with respect to the protection of human health and protection of land ecosystems, crops and materials. The principal of the AQD is the achievement of air quality with concentrations of pollutants below established critical levels and loads, which define concentrations or exposures to pollutants below which significant harmful effects on receptors, such as humans, plants, materials or specified sensitive elements of the environment do not occur according to present knowledge. For the aquatic environments, there is the Water Framework Directive (WFD, 2000/60/EC), which covers freshwater, transitional and coastal waters up to 1 nautical mile from the continental baseline, and the MSFD, which handles all marine waters up to the Exclusive Economic Zone. Hence, in coastal waters, there is an overlap, but the MSFD only applies for aspects not already addressed by the WFD, e.g. litter, underwater noise and indicators such as marine mammals. The overarching aim of both WFD and MSFD is that all water bodies in the EU shall reach or maintain good status of waters, habitat and resources. This condition is termed "Good Ecological Status" (GES) in the WFD and "Good Environmental Status" (GES) in the MSFD.

\section{Critical concentration levels and deposition loads of air pollutants}

The methodology for the impact assessment of air pollution from shipping applied in the BONUS SHEBA framework follows the practices of the Thematic Strategy on Air Pollution (TSAP), which established health and environmental interim objectives for the European Union for the year 2020. In line with the TSAP, our framework evaluates impacts on three air quality health impact indicators: 1. Premature mortality (life shortening) from exposure to fine particulate matter $\left(\mathrm{PM}_{2.5}\right)$ with Years of Life Lost (YOLLs) as the quantitative metric; 2. Premature mortality from exposure to enhanced ground level ozone concentrations with cases of premature deaths as a quantitative metric; 3 . In port cities, attainment of air quality limit values for ambient $\mathrm{NO}_{2}$ and $\mathrm{PM}_{2.5}$ concentrations on annual, daily and hourly time scales.

The shipping-related health impacts are assessed from the shipping contributions to $\mathrm{PM}_{2.5}$ and ozone calculated by the CTMs and by the urban-scale air pollution models and the consecutive human exposures in the Baltic Sea region and selected port cities, calculated with help of population maps. The additional mortalities and years of life lost are then calculated using the most recent exposureresponse functions (WHO 2013) and the current and future mortality incidences and life expectancy statistics for the European countries. For these calculations, tools like e.g. the ALPHA-Riskpoll (ARP) tool can be used (Holland et al. 2013). The ARP tool also includes data enabling calculation of the associated external costs.

Deposition of air pollutants on land contributes to acidification and eutrophication of land ecosystems. Two indicators are used to describe the effects on natural ecosystems and forests: (1) The area of ecosystems where biodiversity remains threatened by nitrogen deposition in excess of the critical loads. (2) The forest area threatened by acidification, i.e. receiving acidifying deposition above their critical loads. To calculate the exceedances, the deposition fields from CTM simulations without and with shipping are overlaid with maps of critical loads for nitrogen and acid deposition, respectively (Hettelingh et al. 2017), and the area with exceedances are compared for the two simulations. The increase of ecosystem areas with nitrogen deposition above their critical loads for eutrophication and with nitrogen and sulphur deposition above their critical loads for acidification is then assigned to emissions from shipping.

\section{Assessing impacts on the marine environment}

In the EU, member states are obliged to monitor the condition (or status) of both freshwater and marine ecosystems. The status and conditions of ecosystems are also strongly linked to human wellbeing through ecosystem service as ecosystems need to be in good status to be able to provide multiple ecosystem services. The MSFD defines GES as "The environmental status of marine waters where these provide ecologically diverse and dynamic oceans and seas which are clean, healthy and productive". The MSFD includes 11 qualitative descriptors that help EU member states to interpret what GES means in practice. As highlighted in Fig. 2, shipping affects at least six of these descriptors. Since 2010, HELCOM has been acting as a coordinating platform for the regional implementation of the MSFD in the Baltic Sea and has developed core indicators to be used for monitoring and assessments of environmental state and impacts. In BONUS SHEBA, the indicators and Environmental Quality Standards (EQS) 
developed at EU level (e.g. AQD), on regional scale (HELCOM Core indicators) and on national level (WFD and MSFD) were used in the impact assessment of shipping. Hundreds of unique contaminants were identified to be discharged from shipping. Therefore, the risk characterisation approach using ratios of Predicted Environmental Concentrations and Predicted No-Effect Concentration (PEC/PNEC) was also applied as a complement to predict the cumulative environmental risk of different waste streams (Ytreberg et al. 2020).

\section{Underwater noise}

Loud anthropogenic underwater sounds can have a wide range of harmful impacts on marine animals such as injury, permanent or temporary hearing loss, behavioural responses and masking of biologically relevant signals. Impacts on individuals can have impacts at the population level and further affect whole ecosystems (Slabbekoorn et al. 2010). All fish can detect sound and are vulnerable to underwater noise. However, there are species-specific differences in the sensitivity of hearing and in detection of the particle motion and pressure components of underwater sound. Even though a few studies of underwater noise impacts on animal behaviour exist (Southall et al. 2008; Durate et al. 2021 and the references therein), no common criteria for harmfulness of underwater noise have been agreed and exceedances of the hearing threshold of a species cannot be considered automatically harmful. This hampers the evaluation of underwater noise using the DPSIR framework and a large amount of further work is needed in this topic to map out animal habitats and response to noise exposure.

\section{Impacts}

Here, the BONUS SHEBA framework concentrates on the assessment of impacts of shipping on ecosystem services and on human health from air pollution. The Common International Classification of Ecosystem Services (CICES v. 4.3, http://cices.eu/) contains three main categories of ecosystem services: provisioning, regulation and maintenance, and cultural services. In cases where this is possible, the impact part of the assessment framework also includes valuation of the external costs arising from these impacts to allow for cost-benefit analyses of potential abatement measures when analysing different options for response.

In the framework, the health impacts related to shipping in different scenarios are assessed through comparison of health impacts in model simulations including and excluding the analysed shipping scenario or, optionally, comparing the impacts in the different scenarios. The external costs of shipping-related air pollution associated with the health impacts are performed in the ARP tool together with the health impact assessment. The health impact with the highest monetary value is avoided mortality (fatality), which is valued by either estimating the Value of Statistical Life (VSL) or the Value Of Life Year lost (VOLY). There is a wide range of values for VSL and VOLY available in the literature and ARP assesses the uncertainty interval including costs based on a range of values of VOLY and VSL estimates.

To evaluate effects of acidification and eutrophication related to air pollution from shipping, a modelling framework for describing exceedances of critical loads and levels, also included within the Clean Air for Europe (CAFE) programme cost-benefit analysis methodology (AEAT 2005), is adopted. While information from the literature provides insight on the types of effect that may be anticipated, at this moment, there is a lack of information for going beyond this evaluation. ECLAIRE (2015) suggests three different methods for valuation of ecosystem damages: The first builds on willingness to pay (WTP) for protection of biodiversity, the second on restoration costs of the lost biodiversity and the third approach looks at the cost of measures to reduce emissions in a way that the requirement that the critical loads for acidification and eutrophication in sensitive ecosystem areas are not exceeded at any place. None of these methodologies have been, however, applied for larger regions but individual countries and data that would enable their wider application is still missing.

According to the EEA (2015), provisioning services can be described as all material and biota which represent tangible outputs from marine ecosystems and can be consumed or traded. In the SHEBA approach, impacts on provisioning services are addressed, e.g. as spreading of invasive NIS by shipping, which influence both intermediate ecosystem services such as existing food web structures, and final ecosystem services, such as commercial fish stock. Spreading of NIS is a global problem causing enormous societal costs (Gollasch 2002; Chan et al. 2015), e.g. from increased maintenance costs for industries using seawater for cooling purposes, as well as altered species for commercial fishing. Another type of impact is ship discharges of nutrients that cause increased algal growth and decreased oxygen concentrations, which will have negative impact on cod reproductive volume (Vallin et al. 1999; Raudsepp et al. 2019b). Regulation and maintenance services are the effects of marine biota and ecosystems on biotic and abiotic parameters that are defining peoples' environment ("ambient" environment) (EEA 2015). These outputs of the ecosystem affect the performance of individuals, communities or populations but are not consumed. In our approach, this is represented, e.g. by the influence of shipping on marine biota through emission of different 
contaminants, which then disable waste mediation by algae. Cultural services include non-material outputs from marine ecosystems that have spiritual, intellectual, cultural, physical or experiential significance (EEA 2015). These are physical and experiential interactions with marine biota, such as diving or snorkelling. In our approach, this is exemplified by the contribution by shipping to algal blooms caused by excess nutrients, leading to a loss of number of tourists in recreational areas.

It is well known that it is a big challenge to push the ecosystem services assessment all the way to final ecosystem services and monetary values (Borja et al. 2020).

\section{From impact to response}

The ambition of environmental legislation is to reduce the negative environmental impacts of pollution from different sectors to an acceptable level with highest economic efficiency. It is, therefore, important to quantify the contributions of the different sectors to the ambient levels of different pollutants and their impacts and to target the abatement measures to the sectors with high impact and low abatement costs. To achieve this, apart from the knowledge on costs of the abatement measures, a quantitative knowledge of this complex drivers-pressures-stateimpact system is necessary which is only possible through long-term continuous development and collaboration of scientists from many disciplines.

In the EU, the environmental directives AQD, WFD and MSFD set goals for the state of the environment and pathways to achieve these through a range of quantitative environmental indicators and timed goals. Formulation of the AQD recognises the scientific development, the critical loads and levels are set to prevent the environmental damage according to the present knowledge, and the indicators as well as the methodologies and parameters used are continuously updated. The achievement of the goals of the AQD requires reduction of emission sources which are targeted by a range of directives, e.g. in case of air pollution by the National Emission Ceiling (NEC) Directive (2016/2284/EU) and a number of specific directives including among others emission standards for road vehicles, off road machinery, as well as the Fuel Sulphur Directive and the NOx Technical Code adopting the IMO legislation for emission limits for shipping. The link between the AQD and the NEC with other directives targeting emissions is conveyed by the task forces and programmes of the Convention on Long Range Transport of Air Pollutants (LRTAP), the EU Thematic Strategy on Air Pollution as well as associated expert groups, who continuously absorb the new research into the impact assessment framework supporting the air quality policy work, perform optimisation modelling for abatement strategies and perform cost-benefit analyses for legislation options.

An integrated assessment of contamination status of the Baltic Sea is conducted by HELCOM. It is based on 12 contaminants where environmental concentrations are related to threshold values set by the MSFD. According to the latest assessment, none of the Baltic Sea basins fulfilled good environmental status (HELCOM 2018b). Since shipping emits hundreds of contaminants, national Swedish EQS values for a few additional contaminants (e.g. copper and zinc) developed under the WFD were used in SHEBA. Nonetheless, the vast majority of contaminants emitted from shipping are not routinely monitored under neither WFD nor the MSFD and are hence excluded in assessments of status, pressure and impacts on the Baltic Sea environment, as assessed by HELCOM and EU Member States. In other words, the links between pressure of contaminants from shipping and environmental state and impacts will not be caught in the current regulatory frameworks (MSFD and WFD).

Good environmental status with respect to underwater noise, as defined in the MSFD, requires that the level and distribution of both continuous and impulsive sounds should not cause negative impacts on marine life. Monitoring of underwater sound has been developed by expert groups both on European and Baltic Sea levels to map the underwater noise and to develop quantitative indicators. To this day, however, such levels have not been defined for sound sensitive species in the Baltic Sea (HELCOM 2018a). There are operational and technical measures which could be considered to reduce shipping noise, but such measures have not yet been considered on a large scale. The most evident change which can be adopted immediately is the reduction of vessel speed. This has the co-benefit of reducing fuel consumption and air emissions. See, for example, Matthews et al. (2018).

Within the BONUS SHEBA analytical framework, responses incorporate all possible strategies, such as societal adaptation to new conditions, economic responses, as well as policies and instruments to reduce or mitigate pressures. However, the focus is on policy measures designed to improve the environmental performance of shipping. The framework is applied first to the current situation and then to a set of different future scenarios adopting a set of policies or/and technological measures under certain socioeconomic development. These scenarios provide sensitivity analysis for designing responses needed for shipping to efficiently contribute to the achievement of the environmental and climate goals.

Future scenario modelling is used in the BONUS SHEBA framework to give background material that can be used in the development of policy measures as a response to the impacts that are observed. First, the 
transport work and ship types that are expected in the future are analysed. Then a business as usual scenario (BAU) is constructed, where already decided policy measures also are considered. By constructing emission scenarios for BAU by modifying traffic volumes and emission factors in the STEAM model, total as well as gridded timeresolved emissions can again be calculated and the models for dispersion and transformation of pollutants and contaminants in air and sea described above can be applied. Other scenarios are then constructed in the same fashion to illustrate specific possible policy measures. This could be the introduction of more (or less) stringent emission regulations, an extensive introduction of new fuels, the use of specific abatement measures or modal shift of transport volumes between sea and land. The modelling results are then used to describe the impact on the environment and humans as illustrated earlier. This approach provides detailed analysis of the potential outcome of policy or/and technological measures that can serve as background for decision making.

\section{Response}

Legislation for reduction of environmental pollution and damage is based on ambition to reduce the impacts but targets mostly the state indicators (MSFD, AQD) or the pressures (NEC directive, MARPOL Annexes, Fuel directive). The most comprehensive international work to regulate pollution from ships is the International Convention for the Prevention of Pollution (MARPOL) and its six annexes, which embrace emissions and discharges to both air and sea, and the Ballast Water Convention. An overview of the international legislation regulating pollution from ships and type of pressures targeted is shown in Table 1. Also the United Nations Convention on the Law of the Sea (UNCLOS 1982) embodies in Part XII the fundamental obligation to "prevent, reduce and control pollution of the marine environment", but its definition of pollution is wider. MARPOL requires discharges to be gaseous, liquid or solid, but this is not required in UNCLOS, in which also energy emissions could be considered (heat, light, noise).

Compulsory regulation for ship noise does not exist yet, but voluntary general guidelines have been agreed upon (IMO MEPC.1/Circ.833). The overall goal is to not increase shipping noise by more than $3 \mathrm{~dB} /$ decade, but mandatory design changes for vessel construction principles have not been suggested, yet. It is also unclear how well the existing IMO environmental conventions regulating shipping may cover non-physical emissions, like noise.

The Baltic Sea Region is one of the few emission control areas for sulphur emissions from shipping since 2006. In addition, it became a nitrogen emission control area
(NECA) in 2021. After the implementation of the SECA in the North (2007) and Baltic Seas (2006), and especially after its tightening in 2015, the contribution of shipping to $\mathrm{SO}_{2}$ concentrations in the atmosphere decreased significantly (e.g. Jonson et al. 2019). However, it will take much longer until effects of the NECA will be visible because this only affects newly built ships and at least one full-fleet renewal cycle is needed to determine the full impact on ship emitted $\mathrm{NO}_{\mathrm{x}}$. Also, new vessels are required to fulfil the IMO Energy Efficiency Design Index requirements, which will improve the fuel efficiency of ships in the future.

Recently, the IMO agreed on a roadmap for the reduction of greenhouse gas emissions from ships, which aims at $50 \%$ reduction by 2050 compared with 2008 levels (MEPC 304(72)). This roadmap will need to involve a gradual shift away from fossil fuel use, because the energy efficiency improvements alone are not enough to meet the $50 \%$ reduction target. This target will have a large impact on emissions and discharges of other pollutants and contaminants, as a major load of contaminants from shipping originates from the combustion of residual fossil fuels, with or without exhaust gas cleaning systems. Also, for emissions of underwater noise, a decrease is expected since the primary means of energy efficiency increase is the slow steaming (line IMO MEPC 304(72) in Table 1).

From 2021 onwards, tighter rules for sewage discharges from passenger vessels are in place in the Baltic Sea area. There are exemptions for vessels visiting St Petersburg until 2023, but by that time, all sewage releases from passenger vessels are banned, and it is estimated that this will reduce the nutrient input from sewage by $77 \%$. Grey water discharges from ships are still allowed, though, if they are not mixed with sewage. Nutrients from comminuted food waste released from ships will continue contributing to the total load of nutrients. Over $90 \%$ of food waste nitrogen comes from passenger vessels which are also the major contributor to the discharges of grey water and sewage. The impact of nutrient releases from ships has been studied by Raudsepp et al. (2019a), who identified that shipping contributed to the total loads into the Baltic Sea with $0.3 \%$ of $\mathrm{P}$ and $1.3-3.3 \% \mathrm{~N}$, but these sources were responsible for up to $10 \%$ of various biogeochemical variables.

In 2017, the IMO also mapped its relation to the $17 \mathrm{UN}$ Sustainable Development Goals (SDGs) according to the Agenda 2030 (IMO TC.1/Circ.69) and found itself having an integral role in meeting the SDG targets, especially those of SDG 14 'Life below water'. One important framework to support and develop future regulations to prevent pollution from shipping are the Glo-X partnership projects. So far, the programme embraces the ongoing Global Biofouling Project (GloFouling), and the two 
Table 1 Overview of regulations of shipping subsystems targeting different on-board operations (pathways) and the targeted pressures, expressed in terms of state descriptors of the EU directives. $\mathrm{XX}=$ well known and quantified, $\mathrm{X}=$ well recognised, $\mathrm{h}=$ hypothesised significant

\begin{tabular}{|c|c|c|c|c|c|c|c|c|c|}
\hline \multirow{2}{*}{$\begin{array}{l}\text { Response } \\
\text { Regulatory framework }\end{array}$} & \multirow{2}{*}{$\begin{array}{l}\text { Pressure } \\
\text { Source/pathway }\end{array}$} & \multicolumn{8}{|c|}{ Type of stressor-Pressure/Environmental regulatory framework-State } \\
\hline & & $\begin{array}{l}\text { Invasive } \\
\text { species } \\
\text { MSFD } \\
\text { D2 }\end{array}$ & $\begin{array}{l}\text { Nutrients } \\
\text { MSFD } \\
\text { D5 }\end{array}$ & $\begin{array}{l}\text { Contaminants } \\
\text { MSFD } \\
\text { D8 }\end{array}$ & $\begin{array}{l}\text { Acid. } \\
\text { subst. } \\
\text { MSFD } \\
\text { D7 }\end{array}$ & $\begin{array}{c}\text { Litter \& } \\
\text { particles } \\
\text { MSFD } \\
\text { D10 }\end{array}$ & $\begin{array}{l}\text { Energy } \\
\text { \& noise } \\
\text { MSFD } \\
\text { D11 }\end{array}$ & $\begin{array}{l}\text { Air poll.- } \\
\text { Land } \\
\text { ecosystems } \\
\& \text { crops } \\
\text { AAQD }\end{array}$ & $\begin{array}{l}\text { Air poll.-- } \\
\text { Human } \\
\text { health } \\
\text { AAQD }\end{array}$ \\
\hline IMO MARPOL Annex VI & $\begin{array}{l}\text { Emissions of air } \\
\text { pollutants }\end{array}$ & & $\mathrm{XX}^{\mathrm{a}}$ & $\mathrm{X}^{\mathrm{a}}$ & $\mathrm{X}^{\mathrm{a}}$ & $\mathrm{X}^{\mathrm{a}}$ & & $\mathrm{X}$ & $\mathrm{X}$ \\
\hline IMO MEPC 304(72) & $\begin{array}{l}\text { Emissions } \\
\text { greenhouse } \\
\text { gasses }\end{array}$ & & $\mathrm{XX}$ & $\mathrm{XX}$ & $\mathrm{XX}$ & $\mathrm{XX}$ & $\mathrm{X}$ & $\mathrm{XX}$ & $\mathrm{XX}$ \\
\hline MARPOL Annex I & Bilge water & & $\mathrm{X}$ & $\mathrm{X}$ & & $\mathrm{X}$ & & & \\
\hline $\begin{array}{l}\text { Ballast Water Management } \\
\text { Convention }\end{array}$ & Ballast water & $\mathrm{X}$ & $\mathrm{X}$ & $\mathrm{h}$ & & & & & \\
\hline MARPOL Annex IV & Sewage & & $\mathrm{X}$ & $\mathrm{X}$ & & $\mathrm{h}$ & & & \\
\hline- & Stern tube oil & & & $\mathrm{X}$ & & & & & \\
\hline $\begin{array}{l}\text { AFS convention EU Biocidal Product } \\
\text { Regulation }\end{array}$ & $\begin{array}{l}\text { Biofouling vs } \\
\text { Antifouling } \\
\text { paint }\end{array}$ & $\mathrm{X}$ & & $\mathrm{X}$ & & & & & \\
\hline MARPOL Annex V & $\begin{array}{l}\text { Food waste } \\
\quad \text { (solid) }\end{array}$ & & $\mathrm{X}$ & & & $\mathrm{X}$ & & & \\
\hline $\begin{array}{l}\text { MEPC voluntary guidelines on } \\
\text { reducing underwater noise from } \\
\text { commercial shipping }\end{array}$ & $\begin{array}{l}\text { Propulsion, } \\
\text { vibrations and } \\
\text { cavitation }\end{array}$ & & & & & & $\mathrm{X}$ & & \\
\hline
\end{tabular}

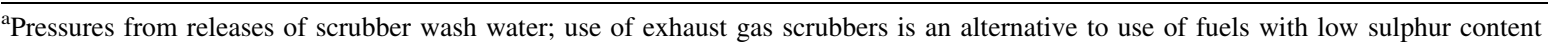

completed projects: The Global Ballast Water Management Project (GloBallast) and the Global Maritime Energy Efficiency Partnerships Project (GloMEEP).

While regulations of shipping subsystems for different on-board operations are set separately, e.g. in the MARPOL Annexes (Table 1), and often based on type approval of emissions from a single subsystem on board, the total amount of one contaminant from a single ship may originate from several subsystems. E.g. copper emitted from a ship may originate from antifouling paints, cooling, bilge and scrubber water. The EU has regulations on the maximum allowed copper concentration in antifouling paints (Biocidal Product Regulation BPR 528/2012); however, there are no regulations for the other subsystems (Turner et al. 2017). To summarise, there are no existing assessments of the total load (pressure) of, e.g. different contaminants originating from shipping. Based on analyses of state change and impacts, the suggested framework enables such analysis and can be used to give input regarding refined or new policy instruments for shipping, e.g. adaptations of MARPOL to the latest scientific findings.

\section{CONCLUSIONS AND OUTLOOK}

In their Ecosystem Overviews, the International Council for the Exploration of the Sea (ICES) aims at assessing the main human Pressures and the associated change in State and Impacts in different regional seas. In the ICES Ecosystem Overview of the Baltic Sea (ICES 2018), the only pressure included from the pressure category "Maritime transport", is introduction of non-indigenous species, which clearly is an underestimation of the total pressure from shipping on the marine environment.

The holistic approach of looking at the impacts of operational shipping on atmospheric, marine and underwater noise pollution simultaneously, based on efficient transfer of knowledge and concepts previously applied on assessments of air pollution to assessments of marine pollution and underwater noise, significantly improves the general understanding of shipping-related impacts. The BONUS SHEBA assessment framework is implementing the current state of knowledge allowing quantitative assessment as far as possible and mapping the path towards a complete quantitative assessment framework. The concerted approach also allows identification of potential synergistic effects, like for example, the impact of slow steaming on fuel consumption savings and associated air pollution and underwater noise reduction.

The new capabilities for modelling of shipping-related water contaminants and underwater noise developed and implemented into the Ship Traffic Emission Assessment Model (STEAM) serve as a cornerstone of the assessment framework for the impacts of shipping. Prior to the 
BONUS SHEBA framework, the use of AIS data to assess marine pollution from shipping had only been applied to model the indirect contribution from shipping emissions through atmospheric deposition. Within this framework, the very first complete inventory and calculation of load factors of waste streams and the sum of pollutants from all waste streams from shipping in the Baltic Sea has been achieved (Jalkanen et al. 2021a). The development of the underwater noise source module of STEAM is the first attempt to indicate the levels of noise emitted by ships based on actual traffic patterns of AIS, advancing our knowledge of spatio-temporal variation of shipping noise and increasing general knowledge of ships as a source of noise pollution (Jalkanen et al. 2018). This framework also facilitates further developments, both in terms of expanding the regional coverage to European and global scales as well as in terms of updating and improving the emission factors of the different pollutants and contaminants as new data becomes available. Regarding the expansion of geographic coverage, global air emissions from shipping have been reported, e.g. by Johansson et al. (2017), while Jalkanen et al. (2021b) report a baseline for global emissions of shipping underwater noise, point out the development over last 7 years and investigate regional noise trends. The paper also includes the impact of COVID-19 on noise and analyses the noise contributions from various vessel types. Modelling of discharges to the sea at the global scale is difficult due to the complicated legislation regulating discharges in different parts of the world. Once the legislative conditions for the discharges have been adequately defined in a model, global applications are possible, at least for some subsystems. One example of global discharge studies is the ICCT report on scrubber effluent releases (Comer et al. 2020). For some subsystems, gaps in knowledge on emission factors specific for different regions hamper development, e.g. impact of salinity on antifouling releases.

An important, yet underutilised concept in assessments of environmental pollution is the use of scenarios linking pollution to societal development. The scenario work, which forms the second cornerstone of the assessment framework, advanced our understanding of impacts of the main drivers of shipping on its environmental sustainability in upcoming decades. The predictions of emissions to air and water as well as of underwater noise for the present time and for a number of scenarios for years 2030 and 2040 for shipping in the Baltic Sea give us insight to the sensitivity of the trends in emissions to the developments in shipping activities, legislation and uptake of new fuels as well as exhaust and waste cleaning technologies (Fridell et al. 2016). The scenario predictions consistent with emissions produced by the STEAM model facilitate further environmental and socio-economic assessments of impacts of shipping in these scenarios.

The atmospheric chemistry and coupled ocean dynamic_biogeochemistry modelling as well as the noise propagation modelling lay the third cornerstone of the framework connecting the pressures from shipping to spatio-temporal distributions of concentrations of pollutants and further to their impacts on environment. The impact of shipping has been analysed in relation to the three EU Directives: AQD, MSFD and WFD (Karl et al. 2019c; Raudsepp et al. 2019a; Maljutenko et al. 2021). These analyses identify the main areas of environmental degradation caused by current shipping and potential improvements or lack of these in different future scenarios. They also help to identify uncertainties and knowledge gaps in a fully quantitative assessment framework. The fourth cornerstone of the BONUS SHEBA assessment framework is the linkage from the pressures of shipping in the Baltic Sea to its effects on ecosystem services and human wellbeing.

The BONUS SHEBA assessment framework should be seen as a basis which will be continuously developing as the system changes and new knowledge becomes available.

Acknowledgments This work has been conducted within the BONUS SHEBA (Sustainable Shipping and Environment of the Baltic Sea region) project which has received funding from BONUS (Art 185), funded jointly by the EU, Innovation Fund Denmark, Estonian Research Council, Academy of Finland, Forschungszentrum Jülich Beteiligungsgesellschaft mbH (Germany), Research Council of Lithuania, National Centre for Research and Development (Poland) and Swedish Environmental Protection Agency with contribution from project platform CSHIPP, subsidy contract \#C006 of Interreg Baltic Sea Region.

Author contributions All authors contributed to the concept and design of the framework described in this paper, each being responsible and developing specific parts: Jana Moldanová: overall concept, assessment of health effects, assessment of Critical loads; Ida-Maja Hassellöv: overall concept, impacts of marine pollution; Volker Matthias: overall concept, air pollution modelling; Erik Fridell: development of future scenarios; Jukka-Pekka Jalkanen: modelling of emissions of air pollutants, underwater noise and discharges to the sea from shipping; impacts of underwater noise; Erik Ytreberg: marine pollution, assessment of PEC/PNEC ratios; Markus Quante: Scenario development, stakeholder elicitation; Jenny, Tröltzsch: Assessment of policy options, economic valuation of impacts; Ilja Maljutenko: Coupled ocean dynamics biogeochemistry modelling; Urmas Raudsepp: Impacts of marine pollution - nutrients, K. Martin Eriksson: Marine pollution - emissions and concentrations of contaminants in the sea. The first draft of the manuscript was written by Jana Moldanova, Ida-Maja Hassellöv and Volker Matthias with contributions from all co-authors on their specific parts. All authors commented on previous versions of the manuscript. All authors read and approved the final manuscript. 


\section{REFERENCES}

Borja, A., J.H. Andersen, C.D. Arvanitidis, A. Basset, L. BuhlMortensen, S. Carvalho, K.A. Dafforn, M.J. Devlin, et al. 2020. Past and future grand challenges in marine ecosystem ecology. Frontiers in Marine Science 7: 362. https://doi.org/10.3389/ fmars.2020.00362.

Burchard, H., and K. Bolding. 2002. GETM-a general estuarine transport model. Scientific documentation. Tech. Rep. EUR 20253 en.

Byun, D.W., and K.L. Schere. 2006. Review of the governing equations, computational algorithms, and other components of the models-3 community multiscale air quality (CMAQ) modeling system. Applied Mechanics Reviews 59: 51-77. https://doi. org/10.1115/1.2128636.

Chan, F.T., H.J. MacIsaac, and S.A. Bailey. 2015. Relative importance of vessel hull fouling and ballast water as transport vectors of nonindigenous species to the Canadian Arctic. Canadian Journal of Fisheries and Aquatic Sciences 72: 1230-1242. https://doi.org/10.1139/cjfas-2014-0473.

Comer, B., Georgeff, E., and Osipova, L. 2020. Air emissions and water pollution discharges from ships with scrubbers. Consulting report, International Council on Clean Transportation. Retrieved May 21, 2021, from https://theicct.org/sites/default/ files/publications/Air-water-pollution-scrubbers-dec2020.pdf.

DNV, 2012. Shipping 2020. Det Norske Veritas (DNV), Norway, www.dnv.com.

Duarte, C.M., L. Chapuis, S.P. Collin, D.P. Costa, R.P. Devassy, V.M. Eguiluz, C. Erbe, T.A.C. Gordon et al. 2021. The soundscape of the Anthropocene ocean. Science, 371, 853, eaba4658, https://doi.org/10.1126/science.aba4658.

ECLAIRE. 2015. D18.4 Scenario analysis to include policy recommendations and advice to other interest groups. Deliverable report of the ECLAIRE (Effects of Climate Change on Air Pollution Impacts and Response Strategies for European Ecosystems) FP7 project.

EEA, 2015. State of Europe's seas. EEA Report 2/2015. Retrieved 12 February 2021 from file:///C:/Users/janam/Downloads/ THAL15102ENN.pdf.

Endres, S., F. Maes, F. Hopkins, K. Houghton, E.M. Mårtensson, J. Oeffner, B. Quack, P. Singh, et al. 2018. A new perspective at the ship-air-sea-interface: The environmental impacts of exhaust gas scrubber discharge. Frontiers in Marine Science 5: 139. https://doi.org/10.3389/fmars.2018.00139.

Eyring, V., I. Isaksen, T. Berntsen, W. Collins, J. Corbett, Ø. Endresen, R. Grainger, J. Moldanová, et al. 2010. Transport impacts on atmosphere and climate: Shipping. Atmospheric Environment 44: 4735-4771.

Faber, J., S. Hanayama, S. Zhang, P. Pereda, B. Comer, E. Hauerhof, W. Schim van der Loeff, T. Smith, et al. 2020. Reduction of GHG emissions from ships; Fourth IMO GHG Study 2020Final report. IMO MEPC 75/7/15. Retrieved February 12, 2021, from https://safety4sea.com/wp-content/uploads/2020/08/ MEPC-75-7-15-Fourth-IMO-GHG-Study-2020-Final-reportSecretariat.pdf.

Fridell, E., H. Winnes, R. Parsmo, B. Boteler, J. Troeltzsch, U. Kowalczyk, J. Piotrowicz, J.-P. Jalkanen, et al. 2016. Future scenarios; Deliverable 1.4: Report of the BONUS SHEBA project. Retrieved February 11, 2021, from https://sheba-project. eu/imperia/md/content/sheba/deliverables/sheba_d1.4_final.pdf.

Gollasch, S. 2002. The importance of ship hull fouling as a vector of species introductions into the North Sea. Biofouling 18: 105-121. https://doi.org/10.1080/08927010290011361.

Hassellöv, I.M., D.R. Turner, A. Lauer, and J.J. Corbett. 2013. Shipping contributes to ocean acidification. Geophysical
Research Letters 40: 2731-2736. https://doi.org/10.1002/grl. 50521.

HELCOM. 2018a. State of the Baltic Sea-Second HELCOM holistic assessment 2011-2016. Baltic Sea Environment Proceedings $\mathrm{n}^{\circ} 155$, Retrieved February 12, from http://stateofthebalticsea. helcom.fi/about-helcom-and-the-assessment/downloads-anddata/.

HELCOM. 2018b. HELCOM Thematic assessment of hazardous substances 2011-2016. Baltic Sea Environment Proceedings $\mathrm{n}^{\circ} 157$. Retrieved February 12, from https://www.helcom.fi/wpcontent/uploads/2019/08/HELCOM_Thematic-assessment-ofhazardous-substances-2011-2016_pre-publication.pdf.

Hettelingh J.-P., M. Posch, and J. Slootweg (eds.). 2017. European critical loads: database, biodiversity and ecosystems at risk; CCE Final Report 2017, Coordination Centre for Effects. RIVM Report 2017-0155, Bilthoven, Netherlands. Retrieved February 12, from https://www.rivm.nl/publicaties/european-criticalloads-database-biodiversity-and-ecosystems-at-risk-cce-finalreport.

Holland, M., P. Watkiss, S. Pye, A. de Oliviera, and D. Van Regemorter. 2005. Cost-Benefit Analysis of the Thematic Strategy on Air Pollution for Service Contract for carrying out costbenefit analysis of air quality related issues, in particular in the clean air for Europe (CAFE) programme. AEAT/ED48763001/ Thematic Strategy. Retrieved February 12, 2021, from https://ec. europa.eu/environment/archives/cafe/general/pdf/cba_thematic strategy_0510.pdf.

Holland, M.R., S. Pye, and G. Jones. 2013. EC4MACS Modelling Methodology-The ALPHA Benefit Assessment Model. European Consortium for Modelling of Air Pollution and Climate Strategies-EC4MACS.

Hurley, P.J., W.L. Physick, and A.K. Luhar. 2005. TAPM: A practical approach to prognostic meteorological and air pollution modelling. Environmental Modelling \& Software 20: 737-752.

ICES 2018. ICES Ecosystem Overviews, Baltic Sea Ecoregion. v2. 21 January 2019. pp 1-25, https://doi.org/10.17895/ices.pub.4665.

Jalkanen, J.-P., A. Brink, J. Kalli, H. Petterson, J. Kukkonen, and T. Stipa. 2009. A modelling system for the exhaust emissions of marine traffic and its application in the Baltic Sea area. Atmospheric Chemistry and Physics 9: 9209-9223. https://doi. org/10.5194/acp-9-9209-2009.

Jalkanen, J.-P., L. Johansson, J. Kukkonen, A. Brink, J. Kalli, and T. Stipa. 2012. Extension of an assessment model of ship traffic exhaust emissions for particulate matter and carbon monoxide. Atmospheric Chemistry and Physics 12: 2641-2659. https://doi. org/10.5194/acp12-2641-2012.

Jalkanen, J.-P., L. Johansson, M. Liefvendahl, R. Bensow, P. Sigray, M. Östberg, I. Karasalo, M. Andersson, et al. 2018. Modelling of ships as a source of underwater noise. Ocean Science 14: 1373-1383. https://doi.org/10.5194/os-14-1373-2018.

Jalkanen, J.-P., L. Johansson, M. Wilewska-Bien, L. Granhag, E. Ytreberg, K.M. Eriksson, D. Yngsell, I.-M. Hassellöv, et al. 2021a. Modeling of discharges from Baltic Sea shipping. Ocean Science 17: 699-728. https://doi.org/10.5194/os-17-699-2021.

Jalkanen, J.-P., L. Johansson, M. H. Andersson, E. Majamäki, and P. Sigray. 2021b. Underwater noise from ships during 2014-2020. Manuscript submitted to Science Advances.

Johansson, L., J.-P. Jalkanen, and J. Kuukkonen. 2017. Global assessment of shipping emissions in 2015 on a high spatial and temporal resolution. Atmospheric Environment 167: 403-415. https://doi.org/10.1016/j.atmosenv.2017.08.042.

Jonson, J.E., M. Gauss, J.-P. Jalkanen, and L. Johansson. 2019. Effects of strengthening the Baltic Sea ECA regulations. Atmospheric Chemistry and Physics 19: 13469-13487. https:// doi.org/10.5194/acp-19-13469-2019. 
Karl, M., J.E. Jonson, A. Uppstu, A. Aulinger, M. Prank, J.P. Jalkanen, L. Johansson, M. Quante, et al. 2019a. Effects of ship emissions on air quality in the Baltic Sea region simulated with three different chemistry transport models. Atmospheric Chemistry and Physics 19: 7019-7053. https://doi.org/10.5194/acp-197019-2019.

Karl, M., S.-E. Walker, S. Solberg, and M.O.P. Ramacher. 2019b. The Eulerian urban dispersion model EPISODE-Part 2: Extensions to the source dispersion and photochemistry for EPISODE-CityChem v1.2 and its application to the city of Hamburg. Geoscientific Model Development 12: 3357-3399. https://doi.org/10.5194/gmd-12-3357-2019.

Karl, M., J. Bieser, B. Geyer, V. Matthias, J.-P. Jalkanen, L. Johansson, and E. Fridell. 2019c. Impact of a nitrogen emission control area (NECA) on the future air quality and nitrogen deposition to seawater in the Baltic Sea region. Atmospheric Chemistry and Physics 19: 1721-1752. https://doi.org/10.5194/ acp-19-1721-2019.

Maljutenko, I., I.-M. Hassellöv, K.M. Eriksson, E. Ytreberg, D. Yngsell, L. Johansson, J.-P. Jalkanen, M. Kõuts, et. al. 2021. Modelling spatial dispersion of contaminants from shipping lanes in the Baltic Sea. Marine Pollution Bulletin, submitted manuscript MPB-D-21-00896.

Matthews, M.-N. R., Z. Alavizadeh, D. E. Hannay, L. Horwich, and H. Frouin-Mouy. 2018. Assessment of vessel noise within the southern resident killer whale critical habitat: Final Report. Document number 01618, Version 2.1. Technical report by JASCO Applied Sciences for the Innovation Centre, Transport Canada/Government of Canada. Retrieved May 21, 2021, from https://iaac-aeic.gc.ca/050/documents/p80054/129319E.pdf.

Neumann, T. 2000. Towards a 3D-ecosystem model of the Baltic Sea. Journal of Marine Systems 25: 405-419. https://doi.org/10.1016/ S0924-7963(00)00030-0.

Ramacher, M.O.P., L. Tang, J. Moldanová, V. Matthias, M. Karl, E. Fridell, and L. Johansson. 2020a. The impact of ship emissions on air quality and human health in the Gothenburg area-Part II: Scenarios for 2040. Atmospheric Chemistry and Physics 20: 667-10686. https://doi.org/10.5194/acp-20-10667-2020.

Ramacher, M.O.P., V. Matthias, A. Aulinger, M. Quante, J. Bieser, and M. Karl. 2020b. Contributions of traffic and shipping emissions to city-scale NOx and PM25 exposure in Hamburg. Atmospheric Environment. https://doi.org/10.1016/j.atmosenv. 2020.117674.

Raudsepp, U., I. Maljutenko, M. Kã Bien, I.-M. Hassellöv, K.M. Eriksson, L. Johansson, et al. 2019a. Shipborne nutrient dynamics and impact on the eutrophication in the Baltic Sea. Science of The Total Environment 671: 189-207. https://doi.org/10.1016/j.scitotenv.2019.03.264.

Raudsepp, U., I. Maljutenko, and M. Kõuts. 2019b. Cod reproductive volume potential in the Baltic Sea. In: Copernicus Marine Service Ocean State Report, Issue 3. Journal of Operational Oceanography, 12(sup1): s26-s30. https://doi.org/10.1080/ 1755876x.2019.1633075.

Robinson, L.A., F.E. Culhane, C. Baulcomb, H. Bloomfield, A. Boehnke-Henrichs, P. Breen, F. Goodsir, S.S. Hussain et al. 2014. Towards delivering ecosystem-based marine management: The ODEMM Approach. Deliverable 17, EC FP7 Project (244273) 'Options for Delivering Ecosystem-based Marine Management'. University of Liverpool. ISBN: 978-0-90637089-6: $96 \mathrm{pp}$

Sairanen, E. 2014. Baltic Sea underwater soundscape-Weather and ship induced sounds and the effect of shipping on harbor porpoise (Phocoena phocoena) activity. MSc Thesis. Department of Environmen-tal Sciences. University of Helsinki. 67 p.

Slabbekoorn, H., N. Bouton, I. van Opzeeland, A. Coers, C. ten Cate, and A.N. Popper. 2010. A noisy spring: the impact of globally rising underwater sound levels on fish. Trends in Ecology \& Evolution 25: 419-427. https://doi.org/10.1016/j.tree.2010.04. 005.

Sofiev, M., J.J. Winebrake, L. Johansson, E.W. Carr, M. Prank, J. Soares, J. Vira, R. Kouznetsov, et al. 2018. Cleaner fuels for ships provide public health benefits with climate tradeoffs. Nature Communications 9: 406. https://doi.org/10.1038/s41467017-02774-9.

Southall, B.L., A.E. Bowles, W.T. Ellison, J.J. Finneran, R.L. Gentry, C.R. Greene Jr., D. Kastak, D.R. Ketten, et al. 2008. Marine mammal noise exposure criteria: Initial scientific recommendations. Aquatic Mammals 33: 273-275. https://doi.org/10.1080/ 09524622.2008 .9753846$.

Tang, L., M.O.P. Ramacher, J. Moldanová, V. Matthias, M. Karl, L. Johansson, J.-P. Jalkanen, K. Yaramenka, et al. 2020. The impact of ship emissions on air quality and human health in the Gothenburg area-Part 1: 2012 emissions. Atmospheric Chemistry and Physics 20: 7509-7530. https://doi.org/10.5194/acp-207509-2020.

Ten Hallers-Tjabbes, C.C., F.J. Kemp, and J.P. Boon. 1994. Imposex in whelks (Buccinum undatum) from the open North Sea: Relation to shipping traffic intensities. Marine Pollution Bulletin 28: 311-313. https://doi.org/10.1016/0025-326X(94)90156-2.

Turner, D.R., I.-M. Hassellöv, E. Ytreberg, and A. Rutgersson. 2017. Shipping and the environment: Smokestack emissions, scrubbers and unregulated oceanic consequences. Elementa Science of the Anthropocene 5: 45. https://doi.org/10.1525/elementa.167.

UNCLOS. 1982. United Nations Convention on the Law of the Sea. Retrieved January 5, 2021, from https://www.un.org/Depts/los/ convention_agreements/texts/unclos/unclos_e.pdf

Vallin, L., A. Nissling, and L. Westin. 1999. Potential factors influencing reproductive success of Baltic Cod, Gadus morhua: A review. Ambio 28: 92-99.

Van Der Graaf, A.J., M.A. Ainslie, M. Andre, K. Brensing, J. Dalen, R.P.A. Dekeling, S. Robinson, M.L. Tasker et al. 2012. European Marine Strategy Framework Directive-Good Environmental Status (MSFD GES): Report of the Technical Subgroup on Underwater Noise and Other Forms of Energy. Ltd, T. N. M. (Ed.). Brussels, Retrieved February 12, from https://ec.europa.eu/environment/marine/pdf/MSFD_ reportTSG_Noise.pdf.

van Hattum, B., A.C. Baart, and J.C. Boon. 2002. Computer model to generate predicted environmental concentrations (PECs) for antifouling products in the marine environment, 2nd edition accompanying the release of Mam-Pec version 1.4. E-02-04 / Z 3117. IVM, Vrije Universiteit, Amsterdam, The Netherlands. Retrieved January 5, 2021, from https://www.deltares.nl/app/ uploads/2015/04/MAMPEC-background-documentation-v1.4Main_Report_pdf

WHO. 2013. Health risks of air pollution in Europe-HRAPIE project: Recommendations for concentration-response functions for cost-benefit analysis of particulate matter, ozone and nitrogen dioxide. Retrieved January 5, 2021, from http://www. euro.who.int/_data/assets/pdf_file/0006/238956/Health_risks_ air_pollution_HRAPIE_project.pdf.

Ytreberg, E., M. Eriksson, I. Maljutenko, J.-P. Jalkanen, L. Johansson, I.-M. Hassellöv, and L. Granhag. 2020. Environmental impacts of grey water discharge from ships in the Baltic Sea. Marine Pollution Bulletin 152: https://doi.org/10.1016/j. marpolbul.2020.110891.

Publisher's Note Springer Nature remains neutral with regard to jurisdictional claims in published maps and institutional affiliations. 


\section{AUTHOR BIOGRAPHIES}

Jana Moldanová $(\varangle)$ is a Senior Researcher at IVL, Swedish Environmental Research Institute. Her research includes wide range of topics in atmospheric chemistry and air pollution from processes in the free troposphere to urban and indoor environment, often focusing on environmental impacts of the transport sector.

Address: IVL Swedish Environmental Research Institute, Box 530 21, 40014 Gothenburg, Sweden.

e-mail: jana.moldanova@ivl.se

Ida-Maja Hassellöv is a Professor at Maritime Studies at Chalmers University of Technology. Her research stretches from ecotoxicological studies of different waste streams from ships, via perturbation of natural biogeochemical processes by mixing of water in shipping lanes, to valuation of environmental impact from shipping in terms of degradation of ecosystem services.

Address: Mechanics and Maritime Sciences, Chalmers University of Technology, Campus Lindholmen, 41296 Gothenburg, Sweden. e-mail: ida-maja@chalmers.se

Volker Matthias is a Head of the Department "Chemistry Transport Modelling" at the Hereon Institute of Coastal Environmental Chemistry, Helmholtz-Zentrum hereon $\mathrm{GmbH}$. His research focus is on emissions, transport and transformation of pollutants in the atmosphere, since several years impacts of ship emissions on the environment are an important aspect of his work.

Address: Hereon Institute of Coastal Environmental Chemistry, Helmholtz-Zentrum hereon GmbH, Max-Planck-Straße 1, 21502 Geesthacht, Germany.

e-mail: volker.matthias@hereon.de

Erik Fridell is an Assistant Director and Team Leader for the Transport and Mobility group at IVL Swedish Environmental Research Institute and Adjunct Professor in Maritime Environment at Chalmers University of Technology. He has long experience on research about emission to air from traffic including emission modelling and research on emission abatement strategies.

Address: IVL Swedish Environmental Research Institute, Box 530 21, 40014 Gothenburg, Sweden.

e-mail: erik.fridell@ivl.se

Jukka-Pekka Jalkanen is a Senior Researcher at Finnish Meteorological Institute. He is the lead developer of Ship Traffic Emission Assessment Model (STEAM). He is also responsible for annual emission reporting of Baltic Sea shipping for the benefit of the Helcom member states.

Address: Atmospheric Composition, Finnish Meteorological Institute, Erik Palmen's Square 1, 00560 Helsinki, Finland.

e-mail: Jukka-Pekka.Jalkanen@fmi.fi

Erik Ytreberg is a Senior Researcher at Maritime Studies at Chalmers University of Technology. His research focuses on assessing the environmental impact of shipping through the DPSIR concept (Driver-Pressure-State-Impact-Response), as well as on antifouling techniques and how to optimise the performance and minimise the environmental impact of antifouling paints.

Address: Mechanics and Maritime Sciences, Chalmers University of Technology, Campus Lindholmen, 41296 Gothenburg, Sweden.

e-mail: erik.ytreberg@chalmers.se

Markus Quante is a Senior Research Scientist at the Hereon Institute of Coastal Environmental Chemistry, Helmholtz-Zentrum hereon $\mathrm{GmbH}$ and Honorary Professor at Leuphana University Lüneburg. His research includes airborne turbulence measurements and cloud remote sensing as well as chemistry transport modelling. Recently, he has coordinated a climate change assessment for the entire North Sea region (NOSCCA).

Address: Hereon Institute of Coastal Environmental Chemistry, Helmholtz-Zentrum hereon GmbH, Max-Planck-Straße 1, 21502 Geesthacht, Germany.

e-mail: markus.quante@hereon.de

Jenny Tröltzsch is a Senior Fellow at Ecologic Institute. Her research focuses on costs and benefits valuation of environmental goods and services, climate adaptation, the European emissions trading system (EU-ETS), as well as climate mitigation and resource politics. In addition, she coordinates the Institute's activities on Adaptation issues.

Address: Ecologic Institute, Pfalzburger Strasse 43/44, 10717 Berlin, Germany.

e-mail: jenny.troeltzsch@ecologic.eu

Ilja Maljutenko is a Researcher at the Department of Marine Systems, Tallinn University of Technology. His research includes numerical modelling of marine physical and biogeochemical processes.

Address: Department of Marine Systems, Tallinn Technical University, Akadeemia Tee 15A, 12618 Tallinn, Estonia.

e-mail: ilja.maljutenko@taltech.ee

Urmas Raudsepp is a Professor at the Department of Marine Systems, Tallinn University of Technology. His research focuses on numerical modelling of marine physical and biogeochemical processes.

Address: Department of Marine Systems, Tallinn Technical University, Akadeemia Tee 15A, 12618 Tallinn, Estonia.

e-mail: urmas.raudsepp@taltech.ee

K. Martin Eriksson is a Scientist and Group Leader at the Gothenburg Centre for Sustainable Development, Chalmers University of Technology. His research interests include marine ecotoxicology and science for sustainable development.

Address: Mechanics and Maritime Sciences, Chalmers University of Technology, Campus Lindholmen, 41296 Gothenburg, Sweden. Address: Gothenburg Center for Sustainable Development, Chalmers University of Technology, Aschebergsgatan 44, 41133 Gothenburg, Sweden

e-mail: martin.eriksson@chalmers.se 